\title{
Central European Foreign Exchange Markets: A Cross-Spectral Analysis of the 2007 Financial Crisis
}

\section{Introduction}

Following the collapse of Lehman Brothers and AIG in September 2008, like many other economies, countries of Central Europe were subject to negative growth and currency turbulence. Although this period is accepted as a marker in the current global financial crisis, the timeline of events in the credit crisis (Bank of England, 2008) shows BNP Paribas' suspension of three sub-prime money market funds and the European Central Bank injecting $€ 95$ bn to boost liquidity in the European banking sector on $9^{\text {th }}$ August 2007 were the markers of a change. Money market funds dried-up, precipitating the collapse of Northern Rock in the UK a month later.

A member of the European Union wishing to join the Eurozone must maintain their currency within a framework called ERMII, where it is obliged to shadow the Euro for two years, regardless of financial events, which, for an applicant country, presents a potential hazard (Van Poeck et al., 2007). Of the Czech Republic, Hungary, Poland and Slovakia (the CE countries), only Slovakia had formally accepted the ERMII constraints and was rewarded with accession to the Euro on $1^{\text {st }}$ January 09. Given the explicit commitment to an exchange rate, this two-year window left Slovakia more exposed to speculatory attacks than the others. Yet Syriopoulos (2007) proposes that these CE economies would orientate macroeconomic policy towards tracking the Euro in advance of entry, regardless of an ERMII agreement, so were all exposed in some way.

As Figure 1 shows, three of the four of the CE countries are trade orientated, particularly with the European Union. Slovakia is the most trade-dependent on Europe, as measured by trade/GDP, whereas Poland, the largest of the four, is less 'open'. 
Figure 1. Trade Dependence on Europe, selected countries

A further link between these four EU members and some Eurozone countries is banking. Potential ERMII membership reduced the perceived costs of a cross-border loan to both banks and borrowers. Significant proportions of loans were issued by Western European banks in Swiss Francs and Euros, resulting in $66 \%$ of outstanding debt being denominated in foreign currencies in Hungary and 33\% in Poland (IMF, 2009). A depreciation against the Euro could dramatically increase local mortgage repayments, cripple the local housing markets and wound creditor banks headquartered in Western Europe.

Typically, a 'financial crisis' is marked by a sudden halt of normal capital flows. This is preceded by a surge in capital inflows, leaving customers highly leveraged when the evaporation occurs (Kaminsky et al. 2003). With a shortage of liquidity, international banks restrict credit facilities in host nations and repatriate funds to the home country, reversing the flow of capital. A case in point concerns the 2009 Vienna Initiative, an agreement brokered by the International Monetary Fund, for Western European banks with significant exposure to Eastern Europe to maintain lending at 2008 levels. By November 2011, Austria was seeking to impose curbs on its banks' future lending in that region (Wagstyl \& Buckley, 2011), leading to calls for a Vienna 2.0 .

Central European currency markets would be affected by the turbulence in the Eurozone, a phenomenon described as financial contagion. There was an abrupt halt in normal money market functions in August 2007. Moreover, there remain strong trading, banking and exchange rate links between the members of the Eurozone and the $\mathrm{CE}$ countries through which turbulence could be transmitted. What is investigated here is 
whether this 'crisis' led to significant changes in co-movements of these four Central European currencies relative to the Euro.

The work covers the year to August 2007 (the tranquil period) and the year after (the contagious period). During this second year, the banking crisis became evident in the US and Western Europe, but it concludes before the Lehman Brothers' collapse. The issues considered are: first, whether the currencies of the four CE countries were subject to contagion; second, if so, is there evidence of a non-linear change?; and third, is there a difference between the dynamics of Slovakian Koruna and the others? The first issue is considered by investigating correlation and coherence values; the second, draws on cospectra and phase analyses; whilst the third will be addressed throughout the paper.

The paper is compiled as follows. In section two, there is a discussion of foreign exchange rate market dynamics, portfolio theory and contagion. In section three, a review of literature concerning financial contagion over numerous crises is undertaken. Sections four and five review the methods and data utilised. It is shown in section six that there is greater co-movement among the currencies in the contagious period, which, in a managed exchange rate regime, is a favourable change. Moreover, the structure of the co-movement alters. There is a shift towards the higher frequency portion of the cross-spectral decomposition of covariance, which could reflect heightened market turbulence, perhaps induced by noise traders. It is concluded in section seven that the frequency domain reveals widespread contagion and hidden structural changes in variances and covariances. The results are consistent with a directional change in the flow of funds between Eurozone and the four countries. Slovakia is the most exposed and least affected of the four CE countries, a reflection, perhaps, of its formal commitment to EMU. But it is not immune to additional turbulence. 


\section{Exchange Rate Co-movements}

Modern portfolio theory advocates that investors should manage risk through diversification across a variety of assets. Diversification is based on the view that each asset [type] is a function of a distinctive group of drivers (Hoesli et al., 1997). A contagious financial crisis can raise the risk profile of the portfolio by altering the dynamics of the assets within the portfolio such that the degree of distinctiveness is reduced. More similar co-movement or heightened 'intensification' between managed exchange rates implies a favourable change. In the cases of the $\mathrm{CE}$ currencies, one would anticipate a crisis in the Eurozone would induce a greater dissimilarity of comovement, triggering speculation about abandoning an implicit ERMII commitment.

For Forbes and Rigobon (2002), 'contagion must be something more than normal market interdependence; the change in co-movement must be sufficient to amplify the transmission of shocks beyond the idiosyncratic; there must be significant 'intensification' of the link'. They claim that some correlation tests over reject a null of interdependence. Providing a more general framework, Pericoli and Sbracia (2003) define [shift] contagion as 'a structural change in the transmission channels between markets after a shock'. The focus on structural change here entails an analysis of comovements in the contagious era contrasted against that of the tranquil period, by frequency.

The Efficient Market Hypothesis (EMH) has it that asset prices should not deviate, persistently, from economic fundamentals. If a currency is characterised by the EMH, it should follow a random walk and change is driven by externally-generated, random shocks. However, according to Savit (1988), it is possible to explain many price fluctuations without appealing to stochastic effects. Rather, non-linear feedback 
mechanisms in market modelling raise the possibility of a price being characterised by deterministic market dynamics, completely. Copeland (2005) shows that, by altering the only coefficient in a model, a family of periodic patterns can be simulated. As Cuthberston (1996) notes, it is not difficult to set up a model involving a pool of heterogeneous dealers of noise [or irrational] traders and some rational traders [arbitragers] that would simulate a chaotic process (e.g. Bischi and Valori, 2000). Sbracia and Zaghini (2001) show that financial agents, uncertain about fundamentals and others' interpretations of the current signals, may jump from coordinating around one exchange rate to another in a multi-equilibria world. Herding behaviour among speculators (Kaminsky et al., 2003) and rule of thumb portfolio management (Pericoli and Sbracia 2003) are explanations for contagion in financial models. Similarly, contagion may occur where the group of emerging economies have a common risk factor, such as a bank (Kaminsky et al.).

\section{Literature Review}

Intensification of co-movement is established in many papers by splitting the sample into sub-periods and comparing a tranquil period(s) with a contagious one(s). Commonly, a schism between periods reflects an acknowledged beginning of a period of turmoil, such as $17^{\text {th }}$ of October 1987, which is used by Forbes and Rigobon's (2002) in their analysis of the US stock market crash.

Error correction models (ECM) have been used for revealing contagion (e.g. AuYong et al., 2004: Masih and Masih, 1997; 2004: Syriopoulos, 2007: Yang et al., 2003). Their properties, such as the number of cointegrating vectors and the scope to assess Granger causality, are utilised to gauge bond-intensity or the number of links. 
Alternatively, authors have compared tranquil, with contagious period correlation coefficients. Intensification implies the contagious period's correlation coefficient is greater than the one for the tranquil era (e.g. Collins and Gavron, 2005: Corsetti et al., 2005: Forbes and Rigobon, 2002: Gelos and Sahay, 2001: Serwa and Bohl, 2005). Contagion is associated with greater market volatility. Based on the assumption of homoskedasticity, undertaking a comparison of coefficients when heteroskedasticity is likely, would bias the result toward finding contagion. To reduce the likelihood of confusing intensification with greater interdependence, Forbes and Rigobon (2002) adjust for the likely upward bias in the contagion-period correlation coefficient, which, they report lowers the probability of finding contagion. Pericoli and Sbracia comment that, although the adjustment accommodates heteroskedasticity, it may lead to accepting the null of no contagion too often.

Syriopoulos (2007) finds that monetary union in 1999 does not strengthen links between emerging stock markets and those of the US and Germany. To establish this, he considers the stock market indices of the Czech Republic, Slovakia, Hungary and Poland, pre- and post-EMU creation. The post-EMU period is characterised by weaker, short run links among the emerging markets, with Slovakia, in particular, following a more autonomous path. Covering a number of contagious periods, including the Asian crisis and Brazilian, Russian and Czech devaluations, Darvas \& Szapáry (2000) find that the predicament of small open economies is unaffected by the exchange rate regime. Also, the Greek commitment to EMU accession reduced pressure on the Drachma during the Russian crisis of 1998.

Yang et al. (2003), find that EMU led to greater integration of larger European and US stock markets. Examining the same phenomenon but using a GARCH-M model, Westermann (2004) finds that, following EMU, daily lead-lag relations between 
France, Germany and Italy disappear. The two approaches proffer similar conclusions: the EMU precipitated greater market integration.

Cross-spectral methods may provide some interesting possibilities for exchange rate analysis. Despite producing random patterns in the time domain, a chaotic system does have a discernable structure in the frequency domain (Cuthberston, 1996). Also, it is possible that, as debt commonly has a fixed maturity, a periodic effect may be exposed in the frequency domain. Smith (2001) examines coherence among pairs of stock market indices for portfolio compilation purposes. Contagion is revealed by a significant rise in coherence. Smith also uses the phase spectra from tranquil and post1987 US stock market crash eras to indicate that the crash caused a structural change in the co-movements of the equity indices.

Analysing 3-month interest rates of European countries during ERM crisis of 1992, Favero and Giavazzi (2002) find non-linearities in the propagation of expectations of a devaluation across Europe. Estimating gain and phase spectra of British 2 and 10-year bond yields, Hughes-Hallett and Richter (2004) use spectral analysis to compare the 'profiles' or patterns of the spectra of the tranquil period with during and after the ERM crisis of 1992/3. Plotting phase from the three eras on the same figure, they show that, from 1993, the profile becomes flat. Using the confidence interval of the phase values from the tranquil era, those from post-1993 are different, indicating a structural change had occurred.

Orlov (2009) considers Asian currencies in the 1997-era. Orlov posits that, in a tranquil era, exchange rate co-movement may be based on the trend component of the series but, in a contagious period, there is a shift to the irregular component, suggesting that the increase in cospectrum values at the higher end of the spectrum is disproportionately great. Thus, a time domain approach may provide misleading 
inferences if there is a structural change in what determines currency co-variations. What is interesting about his contention is that there could be a finding of no intensification, as revealed by correlation methods, but a shift in the cospectrum towards higher frequencies, or shift-contagion.

\section{Methods}

Tests of the change in the relationships between the foreign currency movements are undertaken as follows. First, correlation coefficients between pairs of the currency series in growth rate form are estimated for both the tranquil and contagious periods. They are then transformed using A1 in the appendix. Accepting the null of $r_{1}=r_{2}$ implies that the 'intensity' of exchange rate co-movements remains unaltered. The alternative, $r_{1} \neq r_{2}$, allows for greater or lesser intensity of co-movement.

Second, the procedure is repeated for each pairing but with an adjustment made as identified in A2 and A3 in the appendix to reflect a likely heterogeneity of variance across the tranquil and contagious sub-periods (described as the Forbes-Rigobon approach). The FR adjustment can be applied to either of the two currencies.

Third, the values for power spectrum, phase, [squared] coherence and cospectrum are estimated using a 15-point Parzen lag window by SPSS. The spectrum comprises 128 (angular) frequencies $(f)$, presented as 0.00390625 to 0.5 radians, which corresponds to 256 to 2 periods (days) plus the long run, zero frequency. A radian $\omega_{j}=$ $2 \pi f_{j}$.

The integrated cospectrum provides the unconditional covariance between $X(t)$ and $Y(t)$ whilst the quadrature integrates to zero (Hamilton, 1994). Thus, the cospectrum proffers a breakdown of covariance by frequency. If the cospectrum coefficient is large 
at frequency $f_{j}$, it indicates that $X(t)$ and $Y(t)$ have a high proportion of their covariance at that periodicy. If that is the case in the tranquil but not the contagious period, a structural change has occurred. Squared coherence is the frequency domain's equivalent of the [squared] correlation coefficient in the time domain. It shows the proportion of the linear relation of $X(t)$ and $Y(t)$ at any frequency (Bartels, 1977). The Forbes-Rigobon approach entails a $t$-test of whether a pair of [Fisher-modified] correlation coefficients are different. In the frequency domain, there are 129 orthogonal cross-spectral values. The contagious period's spectral values are set against those of the tranquil era. For this pair, a Mann-Whitney test is not appropriate as it assumes the samples are mutually independent (Conover, 1971: 224), which they clearly are not. Rather, Smith (2001) treats the two samples as related, and the values from each can be matched. Siegel and Castellan (1988: 73) describe matched pairs tests where the sample subjected to 'treatment' can be assessed against a control group. A means of overcoming the need for a separate control group entails using the subjects as their own control. For the purposes here, a split sample uses the spectral values from tranquil period as the control.

The Sign test is useful when the experimenter wishes to establish that the two conditions are different (Siegel and Castellan, 1988: 80). The Sign test does not make any assumptions about the underlying distribution or that all subjects are drawn from the same population. Wilcoxon Signed Ranks test is more powerful than the Sign test as it utilises both the direction and the magnitude of the difference of each matched pair (Siegel and Castellan, 1988: 87), but does assume the differences are symmetrical across the pairs. What is described as the Smith approach entails subjecting matched pairs of coherence values from the tranquil and contagious periods to the Sign and Wilcoxon tests. This procedure has been used by Hau (2009) with cospectrum, rather 
than coherence values, and has been reviewed as an interesting method by Wang (2003b) in his econometrics text.

Orlov undertakes comparisons of cospectra but at the higher frequencies only using the following:

$$
\Delta \operatorname{Cov}^{\text {high }}=\frac{\operatorname{Cov}_{\text {contagious }}^{\text {high }}-\operatorname{Cov}_{\text {tranquil }}^{\text {high }}}{\operatorname{Cov}_{\text {tranquil }}^{\text {high }}} \operatorname{sign}\left(\operatorname{Cov}_{\text {tranquil }}^{\text {high }}\right) \times 100,
$$

where $\operatorname{Cov}_{\text {contagious }}^{\text {high }}=2 \int_{\omega_{1}}^{\pi} \hat{c}_{X Y}(\omega) d \omega$ is the part of the cospectrum for which the covariance is associated with the frequencies above $\omega_{1}$. The sign element in the expression accounts for negative cospectrum figures which, if ignored, could present misleading values. Contagion is said to exist if there is a $10 \%$ increase in the cospectrum in the higher frequencies.

Orlov's second measure entails comparing the time and frequency domain changes: the growth in intensity associated with the higher frequencies is compared with the increase in the covariance (time domain) between the currency pairs. Again, a $10 \%$ threshold is used as an indicator of contagion. Thus, if (1) reveals $200 \%$ growth and covariance rose by $150 \%$, the ratio 1.33 would pass the 1.1 threshold and be indicative of contagion. As Orlov's approach focuses on a disproportionate covariance increase at the higher frequencies, this would imply a non-linear change across the spectrum.

Also, a phase value at a frequency can be used to reveal a delay in the time domain. A given phase value $P_{X Y}\left(\omega_{j}\right)$ can be displayed in the time domain as tau (see appendix). Analysing real-estate and financial asset markets, Wilson and Okunev (1999) utilise the phase value and its time domain equivalent at the peak of cospectra between real estate and stock markets. Sun et al., (2007) use phase values to reveal leads and lags between a residential price index and consumption expenditure. Using national 
property indices from five countries, Liow (2007) considers phase values that are significantly different from zero. When discussing portfolio diversification strategies, Liow translates these phase values into measures in the time domain. In keeping with Wilson and Okunev (1999) and Sun et al., (2007), a positive phase value indicates the first series $X(t)$ is at a later phase of the cycle than the second $Y(t)$ at frequency $\omega_{j}$. Equivalently, $X(t)$ leads $Y(t)$ in the time domain.

Details of Fisher's $Z$ modification, the Forbes-Rigobon adjustment, and information about cross-spectral analysis are outlined in the appendix. For a detailed exposition of spectral analysis, see Harvey (1993) or Jenkins and Watts (1968).

\section{Data}

Data for the nominal, spot foreign exchange rates of the Czech Koruna (CKoruna), Hungarian Forint, Polish Zloty, Slovakian Koruna (SKoruna) and the Euro, all measured in US Dollars, are taken from the Bank of England's statistics website for the period $9^{\text {th }}$ August 2006 to $8^{\text {th }}$ August 2008. This covers 507 daily foreign exchange rates. To highlight trends in the exchange rate movements, plots of the series over two years are displayed in Figures $2 \mathrm{a} \& 2 \mathrm{~b}$. The Forint and the Euro are measured on the left-hand scales, with the scale for the other three found on the right. Note the ' + ' symbol is used to mark the schism, which occurred on $9^{\text {th }}$ August 2007 . There is drift downwards in the levels of the data, suggesting a general appreciation against the Dollar.

Figure 2a. The Forint, the Czech Koruna and the Slovakian Koruna against the US Dollar.

The Forint is measured on the left-hand scale.

Figure $2 \mathrm{~b}$. The Euro and the Zloty against the US Dollar.

The Euro is measured on the left-hand scale. 


\subsection{Unit Root Tests}

The Augmented Dickey-Fuller (ADF) test for unit root involves the expression,

$$
\Delta x_{t}=\alpha+(\rho-1) x_{t-1}+\beta t+\sum_{j=1}^{p} \alpha_{j} \Delta x_{t-j}+\varepsilon_{t}, \quad \varepsilon_{t} \sim \operatorname{iid}\left(0, \sigma_{\varepsilon}^{2}\right)
$$

where the order of the lag polynomial for each series, $p$, is chosen using Akaike's information criterion, and $t$ is a linear trend variable. The null of a unit root is considered by setting the $t$-ratio of the $(\rho-1)$ parameter against critical values from Dickey-Fuller tables. The $t$-ratios in Table 1 are subdivided by the two sub-periods and reported in levels and first differences. Using Microfit 4.1 to test for unit root in each currency in log form, it is found that every series exhibits unit root behaviour.

Table 1. Unit Root Test Results

Consistent with Smith and Orlov, the logarithm of each series is first-differenced, rendering the transformed series to be a rate of return or growth rate. The standard deviations of the growth rates are displayed in Table 2. For each series, the standard deviation is greater in the contagious period compared with the tranquil, which is consistent with the presumption that a crisis increases turbulence. Levene's homogeneous variances test indicates that these increases are significant. The table also shows, using a Kolmogorov-Smirnov test, that there is no sub-sample where there is a significant deviance from the null of normality.

Table 2. Descriptive Statistics of Currency Turbulence 


\subsection{Spectral Data}

Given movable national holidays and leap years, there is a problem with synchronising days. Imperfect synchronicity can lead to poorly defined spikes in the power and cospectra. To address this, the Bank of England data is adapted so that there is an exchange rate for every weekday, whether it is a working day or not. This is achieved by inserting zeros in the differenced series corresponding to non-trading weekdays. The contagious period is defined as the 256 days from Thursday $9^{\text {th }}$ August 2007; whilst the tranquil 256 day period begins on the corresponding Thursday in August 2006.

The Euro's power spectra for the both the tranquil and contagious periods are displayed in Figure 3. As the contagious is always above the tranquil era spectrum, exchange rate volatility (variance) has increased. However, the distribution of variance across the frequencies has altered, also. There are spikes at 0.105 radians ( 2 weeks) and 0.445 radians (less than half a week) in the contagious era spectrum, but no evidence of a series of peaks at any harmonics.

Figure 3. The Power Spectra of the Euro in Tranquil and Contagious Periods

\section{Results}

The results of the comparisons of the pairs of currencies are split into three. First, the correlation coefficients are reported and significant changes are identified. Second, the coherence values are subjected to Wilcoxon Signed Ranks and the Sign tests. Third, cospectra and alterations in the structure of phase across the frequency range are considered. 


\subsection{Time Domain}

The estimated correlation coefficients, presented in Table 3, are of the tranquil and contagious periods. The second column records the Pearson correlation coefficient for a pair of currencies in the contagious period (a). The arrow indicates whether that value is above or below the corresponding one for the tranquil era (b), reported in the third column. The fourth and fifth columns display $p$ - values of the consideration of difference of the [Fisher-modified] Unadjusted and Forbes-Rigobon adjusted coefficients, based on a two-tailed $t$-test with a null of no change. As a revised correlation coefficient is based on a change in variance of one member of an exchange rate couple in the contagious era, there are two results for each Forbes-Rigobon adjusted pair. The $p$ - value quoted is the one that is more likely to support the null.

If, with the Unadjusted correlation coefficients, an $8 \%$ level of significance is used, all bar the Zloty/Forint and Euro/Czech Koruna exhibit contagion. By contrast, the FR approach leaves one with the view that greater interdependence, not intensification is the norm.

Table 3. Correlation Coefficients

\subsection{Frequency Domain}

Replicating Smith's paper, the mean, median, standard deviation and maximum coherence values are reported in Table 4. Consistent with changes in the correlation coefficients, the mean coherence of 0.71 for the Euro/Czech Koruna couple in the tranquil period decreases, as indicated by the arrow, to 0.68 in the contagious era. The median value also declines from 0.72 to 0.68 . The coherence values for both contagious and tranquil periods are not skewed $(-.220,-.394)$ and are distributed normally $([p=$ 
.330], $[p=.426])$.

The two coherence spectra in Figure 4 for the Czech/Euro couple cross each other. The Smith procedure [and in a similar way in Hau (2009), with cospectrum values] entails the null that the contagious period coherence values are no different from the corresponding ones drawn from the tranquil era. This is accepted [ $p=.218$ ] when using the Sign test, but not with the Wilcoxon Signed Ranks test [ $p=.008]$.

Figure 4. Coherence between the Czech Koruna and the Euro

At least eight cases of contagion are signified with the Smith test results. Only the Czech Koruna/Euro and the Zloty/Forint do not exhibit a different intensity in the contagious period and then they are diagnosed by the Sign test only. These findings are consistent with those with the Unadjusted approach and paint a very different picture of contagion across the CE countries compared with the FR results.

Table 4. Coherence Values - Descriptive Statistics and Tests

\subsection{Cospectrum Analysis}

Following the Hau (2009) variation of the Smith procedure, a consideration of differences between cospectra using matched of pairs of values with a Sign and a Wilcoxon Signed Ranks test, indicates all exhibit significantly heightened covariance ( $p$ $<.000)$. The results are not reported. The cospectra between the Euro and the Czech Koruna are displayed in Figure 5. As Orlov proposes, there is an increase in emphasis in the higher frequency spectrum in the contagious era. The power spectra displayed in Figure 3 and the cospectra in Figure 5 appear to have similar patterns. 
Figure 5. Cospectra between the Czech Koruna and the Euro

The higher frequencies are defined as those of 0.4 radians and above (half a week) where there appears to be a rise in the power spectra in Figure 3, and those of 0.45 radians and above, in keeping with Orlov. With the Euro in Figure 3, frequencies beyond 0.40 [0.45] radians account for $19.8 \%$ [9.8\%] of total variance in the tranquil period. This increases to $21.9 \%$ [10.7\%] in the contagious era. The shift of emphasis is greater with the cospectrum. For example, the corresponding figures for the cospectrum of the Euro and the Czech Koruna are 20.3\% [10.76\%] and 25\% [13.44\%], suggesting an 'intensity of co-movement' between the Euro and the Czech Koruna. Expression (1) generates a value of $224.5 \%$ [229.7\%], which is much greater than the $10 \%$ threshold set by Orlov as a marker of contagion. Indeed, there appears to be a general shift in cospectra towards the higher frequencies. The smallest value found in Table 5 is $121 \%$.

Orlov's second measure entails comparing the time and frequency domain increases. Again using the Euro/Czech Koruna couple as the exemplar, the increase in cospectral values associated with 0.4 radians and above is 1.2 times the corresponding time domain covariance rise, which is also above the 1.1 threshold, supporting a proposition of a non-linear change. Looking at the other cases, the Euro/Hungary pairing is the only one that fails to exhibit shift-contagion. However, if the threshold is increased to above 1.3 , only 3 pairs exhibit contagion and these all involve the Slovakian Koruna. With Orlov's measures, structural change is found to be widespread.

Table 5. Orlov's Measures of Non-linear Change in the Cospectrum

\subsection{Phase Diagram Analysis}


Rather than covering all 10-phase diagrams, the major concern, Euro to CE currency contagion limits the analysis to four. A " $x$ " indicates a phase value at a particular frequency in the tranquil period and "O" is the corresponding symbol for a phase value in the contagious era. The two symbols should be laid on one another where there is no change. Figures 6-9 are of tau. If tau is positive, it suggests of the first series $X$ leads the second $Y$ at frequency $\omega_{j}$ by $\tau$ days (Harvey, 1993).

In some cases there is evidence of a switch in delay. For example, in Figure 7, up to 0.07 radians (cycles of just about 3 weeks), the values of tau between the Euro and the Czech Koruna in the tranquil period are negative and in the contagious era they are positive. The Euro leads in the tranquil and lags in the contagious era. Between 0.07 and 0.2 radians (cycles of just about a week), the signs are reversed. The same sort switch can be seen in the other pairings. The delays associated with the Forint and the Czech Koruna (Figures 7 and 8) are of around 11/2 to 2 days, whereas the leads or lags for the Zloty and the Slovakian Koruna (Figures 6 and 9) are fractions of days. The key difference, apart from the clarity, is that the others lead the Euro in the tranquil era, whereas the Czech Koruna lags that reference currency. This needs further investigation.

Figure 6. Tau - Euro/Zloty

Figure 7. Tau - Euro/CKoruna

Figure 8. Tau - Euro/Forint

Figure 9. Tau - Euro/SKoruna 


\subsection{Review}

As one might expect, the Forbes-Rigobon approach reveals far fewer cases of intensification than the Unadjusted correlation approach, at similar levels of significance. The former method suggests that only there is one case of contagion and that is between the Euro and the Slovakian Koruna. Given the commitment to ERMII membership, this might be explained away by successful macroeconomic and exchange rate management. From this, it is concluded that the Slovakian Koruna was subject to contagion in the intensification sense. By contrast, using the more conservative Sign test, the Smith's approach highlights all but two cases, one of which is the Euro/Czech Koruna. In other words, contagion is found to be widespread, if not in all cases; results reminiscent of the 'unreliable' Unadjusted approach.

Cospectral comparisons highlight a general non-linear shift in the frequency domain: heightened volatility in the currency markets favours the higher frequencies. The inference from the Forbes and Rigobon test on the Euro and the Czech Koruna (Table 3) is one of no change. Greater interdependence could reflect a rise in covariance and variances. However, this stability masks a structural transformation (Table 5). There is a disproportionate increase in co-movements among the high frequency components. That is, there has been shift-contagion.

The phase spectra reveal that there are structural changes in the lead-lag relations. In most phase diagrams, most clearly evident in ones involving the Czech Koruna, such as Figure 7, many values appear to have switched sign, most obviously in the lower frequencies. Where there was a lead in the tranquil period, there is a lag in the contagious era, for possibly a similar time period. A possible interpretation, consistent with Kaminsky et al. (2003), is that financial contagion befell them through the common link, the banking sector. The CE countries were beneficiaries of large inflows 
in the early to mid part of the decade. There was a dramatic evaporation of credit in European financial markets. Seeking to bolster their balance sheets, banks panicked, recalled loans, and repatriated funds from CE countries, so that the inflow transmuted into an outflow during the crisis, such occurred in Latvia and Estonia (Levy-Yeyati, 2009; Brixiova, et al., 2009) and the Vienna Initiative sought to prevent. An exception to this switching is the Forint/Zloty pair, which seems to shift towards delays at shorter frequencies.

\section{Conclusion}

Using correlation and spectral methods, this paper considers whether four Central European countries that aspired to join the Euro were subject to financial contagion following events in August 2007. Favero and Giavazzi (2002) conclude that the ERM crisis entailed non-linearities in the propagation of expectations. Their findings are consistent with a large variety of models that describe alternative mechanisms that may lie behind such non-linearities. These include herding behaviour, expectations shifts, liquidity effects and liquidity problems faced by foreign investors. Hughes-Hallett and Richter (2004) and Orlov (2009) find non-linearities in asset co-movements during exchange rate crises using spectral analysis.

Non-linearities are found here, using spectral analysis, within CE currency dynamics and the propagation of currency turbulence. There are two elements to the analysis of contagion. The first is whether there was intensification among the CE four and the Euro. The Forbes and Rigobon's (2002) variance-adjusted, intensification test, reveals far fewer cases of contagion than the variance-unadjusted version. Indeed, of the ten cases examined, only one, the Euro/Slovakian Koruna, exhibits intensification, but 
this is a favourable shift for the only one of the CE four formally committed to the ERMII criteria. A conservative version of Smith's coherence-based method reveals that all but the Euro/Czech Koruna and Forint/Zloty are subject to intensification. There is evidence of widespread contagion.

The second element concerned the nature of the contagion. Is there evidence of non-linear change in the co-movements? The cospectral analyses reveal a shift towards greater co-movement among the higher frequency components of the spectrum. Moreover, the phase spectra reveal that there are structural changes in the lead-lag relations, with many values appearing to switch sign, particularly in the lower frequencies.

In the context of this paper, Forbes and Rigobon's intensification could be viewed as too narrow a view of contagion. Pericoli and Sbracia's (2003) shift-contagion includes intensification but also allows for other structural changes. Structural change, without intensification among elements, alters a portfolio’s risk profile.

One suspects that the change in the cospectrum that Orlov posits is a common reaction to a financial shock as this is the portion of the spectrum that would be affected by noise trading and herding behaviour. Moreover, consistent with Kaminsky et al.'s (2003) the Vienna Initiative is a recognition that banks act as a conduit of a financial contagion.

As the structural changes go beyond mere intensification, co-movements of all of the currencies are found to be subject to non-linear, shift-contagion. If, as Favero and Giavazzi (2002) claim, non-linear changes are widespread during a currency crisis, cross-spectral methods have some useful properties that can be used to expose them, not least as the approach is non-parametric or 'model free' and so not subject to the Lucas (1976) critique of econometric models (Orlov, 2009). 


\section{Acknowledgements}

The author would like to express his appreciation for the constructive criticism provided by two anonymous referees.

\section{References}

AuYong, H., Gan, C. \& Treepongkaruna, S. (2004) "Cointegration and Causality in the Asian and Emerging Foreign Exchange Markets: Evidence from the 1990's Financial Crises”, International Review of Financial Analysis, Vol. 13, No. 4, pp. 479-515.

Bartels, C. (1977) Economic Aspects of Regional Welfare, Income Distribution and Unemployment, Leiden, Holland: Martinus Nijhoff Social Sciences Division.

Bischi, G. \& Valori, V. (2000) "Nonlinear Effects in a Discrete-time Dynamic Model of a Stock Market", Chaos, Solitons and Fractals, Vol. 11, pp. 2103-2121.

Brixiova, Z., Vartia, L. \& Worgotter, A. (2009) "Capital Inflows, Household Debt and the Boom-Bust Cycle in Estonia”, William Davison Institute Working Paper, No. 965.

Collins, D. \& Gavron, S. (2005) "Measuring Equity Market Contagion", Applied Financial Economics, Vol. 15, pp. 531-538.

Copeland, L. (2005) Exchange Rates and International Finance, $4^{\text {th }}$ ed., Harlow, UK: Prentice Hall.

Corsetti, G., Pericoli, M. \& Sbracia, M. (2005) "Some Contagion, Some Interdependence': More Pitfalls in Tests of Financial Contagion", Journal of International Money and Finance, Vol. 24, No.8, pp. 1177-1199.

Conover, C. (1971) Practical Nonparametric Statistics, New York: Wiley. 
Cuthbertson, K. (1996) Quantitative Financial Economics, New York: Wiley.

Darvas, Z. \& Szapáry, G. (2000) "Financial Contagion in Five Small Open Economies:

Does the Exchange Rate Regime Really Matter?", International Finance, Vol. 3, pp. $25-51$.

Dunn, R. (1983) Spectral Analysis and Distributed Lags in Geographical Studies of Local Unemployment: 1. Spectral and Cross Spectral Analysis, Environment and Planning A, Vol. 15, pp. 969-985.

Financial Stability Report, The Bank of England, October 2008, No. 24, www.bankofengland.co.uk.

Forbes, K. \& Rigobon, R. (2002) "No Contagion, Only Interdependence: Measuring Stock Market Co-movements," Journal of Finance, Vol. 57, No. 5, pp. 2223-2261.

Gelos, R. \& Sahay, R. (2001) "Financial Spillovers in Transition Economies", Economic Transition, Vol. 9, pp. 53-86.

Favero, C. \& Giavazzi, F (2002) "Is the International Propagation of Financial Shocks Non-Linear?: Evidence from the ERM”, Journal of International Economics, Vol. 57, pp. 231-246.

Hamilton, J. (1994) Time Series Analysis, Princeton, New Jersey, USA: Princeton University Press.

Harvey, A. (1993) Time Series Models, London: Harvester Wheatsheaf.

Hau, H. (2009) "The Exchange Rate Effect of Multi-Currency Arbitrage", CEPR Discussion Paper, No. 7348.

Hoesli, M., Lizieri, C. \& MacGregor, B. (1997) "Spatial Dimensions of the Investment Performance of UK Commercial Property", Urban Studies, Vol. 34, No. 9, pp. 14751494. 
Hughes-Hallett, A. \& Richter, C. (2004) "Spectral Analysis as a Tool for Financial Policy: An Analysis of the Short-End of the British Term Structure", Computational Economics, Vol. 23, pp. 271-288.

IMF (2009) Global Financial Stability Report: Navigating the Financial Challenges Ahead October http://www.imf.org/external/pubs/ft/gfsr/2009/02/

Jenkins, G. \& Watts, D. (1968) Spectral Analysis and Its Applications, London: HoldenDay.

Kaminsky, G., Reinhart, C. \& Vegh, C. (2003) "The Unholy Trinity of Financial Contagion”, Journal of Economic Perspectives, Vol. 17, No. 4, pp. 51-74.

Levy-Yeyati, E. (2009) "Is Latvia the New Argentina?" http://voxeu.org/index.php?q=node/3683 19/10/2009.

Liow, K. (2007) "Cycles and Common Cycles in Real Estate Markets", International Journal of Managerial Finance, Vol. 3, No.3, pp. 287-305.

Lucas, R. (1976) "Econometric Policy Evaluation: A Critique," Carnegie-Rochester Conference on Public Policy, Vol. 1, No.1, pp. 19-46.

Masih, A. \& Masih, R. (1997) "Dynamic Linkages and the Propagation Mechanism Driving Major International Stock Markets: Evidence from Pre- and Post-Crash Eras", The Quarterly Review of Economics and Finance, Vol. 37, No.4, pp. 859-885.

Masih, R. \& Masih, A. (2004) "Common Stochastic Trends and the Dynamic Linkages Driving European Stock Markets: Evidence from Pre- and Post-October 1987 Crash Eras", The European Journal of Finance, Vol. 10, No.1, pp. 81-104.

Orlov, A. (2009) "A Cospectral Analysis of Exchange Rate Co-movements during the Asian Financial Crisis", Journal of International Financial Markets, Institutions and Money, Vol.19, No.5, pp. 742-758. 
Pericoli, M. \& Sbracia, M. (2003) “A Primer on Financial Contagion”, Journal of Economic Surveys, Vol. 17, No.4, pp. 571-608.

Savit, R. (1988) "When Random is Not Random: An Introduction to Chaos in Market Prices," Journal of Futures Markets, Vol. 8, No.3, pp. 271-289.

Sbracia, M. \& Zaghini, A. (2001) "Expectations and Information in Second Generation Currency Crises Models”, Economic Modelling, Vol. 18, No.2, pp. 203-222.

Serwa, D. \& Bohl, M. (2005) "Financial Contagion Vulnerability and Resistance: A Comparison of European Stock Markets", Economic Systems, Vol. 29, No. 3, pp. 344362.

Siegal, S. \& Castellan, N. (1988) Nonparametric Statistics, New York: McGraw-Hill. Smith, K. (2001) "Pre- and Post-1987 Crash Frequency Domain Analysis among Pacific Rim Equity Markets”, Journal of Multinational Financial Management, Vol. 11, No.1, pp. $69-87$.

Sun, J., Sim, L-L., Hin, K. \& Ho, D. (2007) "The Cyclical Association of Residential Housing Price and Consumption", Journal of Real Estate Portfolio Management, Vol. 13, No.3, pp.219-248.

Syriopoulos, T. (2007) "Dynamic Linkages between Emerging European and Developed Stock Markets: Has the EMU any Impact?", International Review of Financial Analysis, Vol. 16, No.1, pp. 41-60.

Van Poeck, A., Vanneste, J. \& Veiner, M. (2007) "Exchange Rate Regimes and Exchange Market Pressure in the New EU Member States", Journal of Common Market Studies, Vol. 45, No.2, pp. 459-485.

Wagstyl, S. \& Buckley, N. (2011) “Crisis hits Central and Eastern Europe” Financial Times, November 22, 2011. 
Wang, P. (2003a) “A Frequency Domain Analysis of Common Cycles in Property and Related Sectors", Journal of Real Estate Research, Vol. 25, No.3, pp. 325-346.

Wang, P. (2003b) Financial Econometrics: Methods and Models, London: Routledge.

Westermann, F. (2004) "Does the Euro affect the Dynamic Interactions of Stock Markets in Europe? Evidence from France, Germany and Italy", The European Journal of Finance, Vol. 10, No.2, pp. 139-148.

Wilson, P. \& Okunev, J. (1999) "Spectral Analysis of Real Estate and Financial Assets Markets", Journal of Property Investment and Finance, Vol. 17, No.1, pp. 61-74.

Yang, J., Min, I. \& Li, Q. (2003) "European Stock Market Integration: Does EMU Matter?", Journal of Business Finance \& Accounting, Vol. 30, No.9/10, pp. 1253-1276. 


\section{Appendix}

\section{Time Domain}

The test of difference of correlation coefficients is based on the Fisher modification.

The test entails the expression: $\frac{\frac{1}{2} \ln \left(\frac{1+r_{1}}{1-r_{1}}\right)-\frac{1}{2} \ln \left(\frac{1+r_{2}}{1-r_{2}}\right)}{\sqrt{\frac{1}{n_{1}-3}+\frac{1}{n_{2}-3}}} \sim N(0,1)$

where $r_{2}, n_{2}$ are the correlation coefficient and number of data points in the contagious period. As contagion is associated with greater volatility $(h)$ compared with that in the tranquil period $(l)$, the Forbes-Rigobon (2002) method involves an adjustment to the contagious correlation coefficient $r_{2}$.

The adjusted correlation coefficient $r=\frac{r^{u}}{\sqrt{1+\delta\left[1-\left(r^{u}\right)^{2}\right.}}$

where $r^{u}$ is the unadjusted (conditional) correlation coefficient and $\delta=\frac{\sigma_{x x}^{h}}{\sigma_{x x}^{l}}-1$

\section{Frequency Domain}

Autocovariance of $X(t)$ is defined as $\gamma_{X}(k)=E\left[\left(X_{t+k}-\mu\right)\left(X_{t}-\mu\right)\right]$ in the time domain, which is represented as the population spectrum, $s_{X}(\omega)=\frac{1}{2 \pi} \sum_{k=-\infty}^{\infty} \gamma_{X}(k) e^{-i k \omega}$, in the frequency domain. The spectrum of series $X(t)$ can be viewed as the decomposition of the variance of the series into the relative contributions of orthogonal frequencies (Dunn, 1983; Harvey, 1993). It reveals the relative power at each frequency 
corresponding to the variance at each periodicy, so that sharp peaks denote a high concentration. As it symmetrical around $\omega=0$, this is transformed into $s_{X}(\omega)=\frac{1}{2 \pi}\left[\gamma_{0}+2 \sum_{k=1}^{\infty} \gamma_{X}(k) \cos (\omega k)\right]$. In theory, the decomposition entails an infinite number of waves, but, in empirical work, not all the frequencies are present, so Dunn concedes that it is better to assert that it is the relative contribution of groups of wavelengths rather than specific wavelengths. The spectrum covers the range of cycle lengths $(\infty, 2)$, with the longest cycle of infinite length corresponding to the trend or mean of the series. Seasonal factors will produce a peak at seasonal intervals. Harmonics are integer-multiples of fundamental frequencies. If there is a large peak at frequency $\omega_{j}$ there might be ones at $2 \omega_{j}$ and $4 \omega_{j}$ etc.. So a weekly spike reflecting a seven-day contract could be reflected in biweekly or monthly spikes as well.

The cross spectrum is given by $s_{X Y}(\omega)=\frac{1}{2 \pi} \sum_{k=-\infty}^{\infty} \gamma_{X Y}(k)(\cos (\omega k)-i \sin (\omega k))$. This can be broken down in the real and imaginary parts, $s_{X Y}(\omega)=c_{X Y}(\omega)+i q_{X Y}(\omega)$, where the cospectrum is defined as $c_{X Y}(\omega)=\frac{1}{2 \pi} \sum_{k=-\infty}^{\infty} \gamma_{X Y}(k) \cos (\omega k)$ and the quadrature is defined as $-q_{X Y}(\omega)=\frac{1}{2 \pi} \sum_{k=-\infty}^{\infty} \gamma_{X Y}(k) \sin (\omega k)$. The cospectrum between $X$ and $Y$ at frequency $\omega_{j}$ represents the covariance between $X$ and $Y$ at frequency $\omega_{j}$ (Hamilton, 1994). The quadrature spectrum $q_{X Y}\left(\omega_{j}\right)$ is the imaginary part of the cross-spectrum. Coherence is the frequency domain's equivalent of squared correlation. If the coherence is large, it indicates the degree to which $X$ and $Y$ are jointly influenced at a common frequency $\omega_{j}$. The theoretical squared coherence is given by $C_{X Y}{ }^{2}(\omega)=\frac{\left|s_{X Y}(\omega)\right|^{2}}{s_{X}(\omega) s_{Y}(\omega)}$. The phase spectrum measures the phase difference between frequency components of $X$ 
and $Y$. If the two series are aligned or in phase at frequency $\omega_{j}$, the phase value is zero.

The phase value is defined as $\hat{P}_{X Y}\left(\omega_{j}\right)=\tan ^{-1} \frac{-\hat{q}_{X Y}\left(\omega_{j}\right)}{\hat{c}_{X Y}\left(\omega_{j}\right)}$. If the $X(t)$ and $Y(t)$ are related as, $x_{t}=y_{t-1}$ and $y_{t}=\cos (\omega t)$, then $x_{t}=\cos \omega(t-1)$ and $x_{t}=\cos (\omega t-\omega)$. Thus, a time shift of one period in the time domain becomes a one-radian, $\omega$, phase angle delay in the frequency domain (Harvey, 1993). Tau $(\tau)=$ phase value $\div$ angular frequency or $P_{X Y}\left(\omega_{j}\right) / \omega_{j}$ or $\left.P_{X Y}\left(\omega_{j}\right) / 2 \pi f_{j}\right)$. 


\title{
Central European Foreign Exchange Markets: A Cross-Spectral
}

\section{Analysis of the 2007 Financial Crisis}

\begin{abstract}
This paper investigates co-movements between currency markets of Czech Republic, Poland, Hungary, Slovakia and the Euro in the year following the drying up of money markets in August 2007. The paper shows that assessing the degree of foreign currency co-movement by correlation can lead to concluding, erroneously, that financial contagion has not occurred. Using cross-spectral methods, the paper shows that defining contagion as changes in the structure of co-movements of asset prices encompasses more of the complex nature of exchange rate dynamics. What is shown is that, following August 2007, there is increased in the intensity of co-movements, but non-linearly. Focusing on the activities of a mix of banks and currency managers, it is suggested that changes in the structure of currency interaction present an unfavourable view of the contagion experienced by at least three of these currencies.
\end{abstract}

Key Words: contagion, Central European currencies, cross-spectral analysis, ERMII

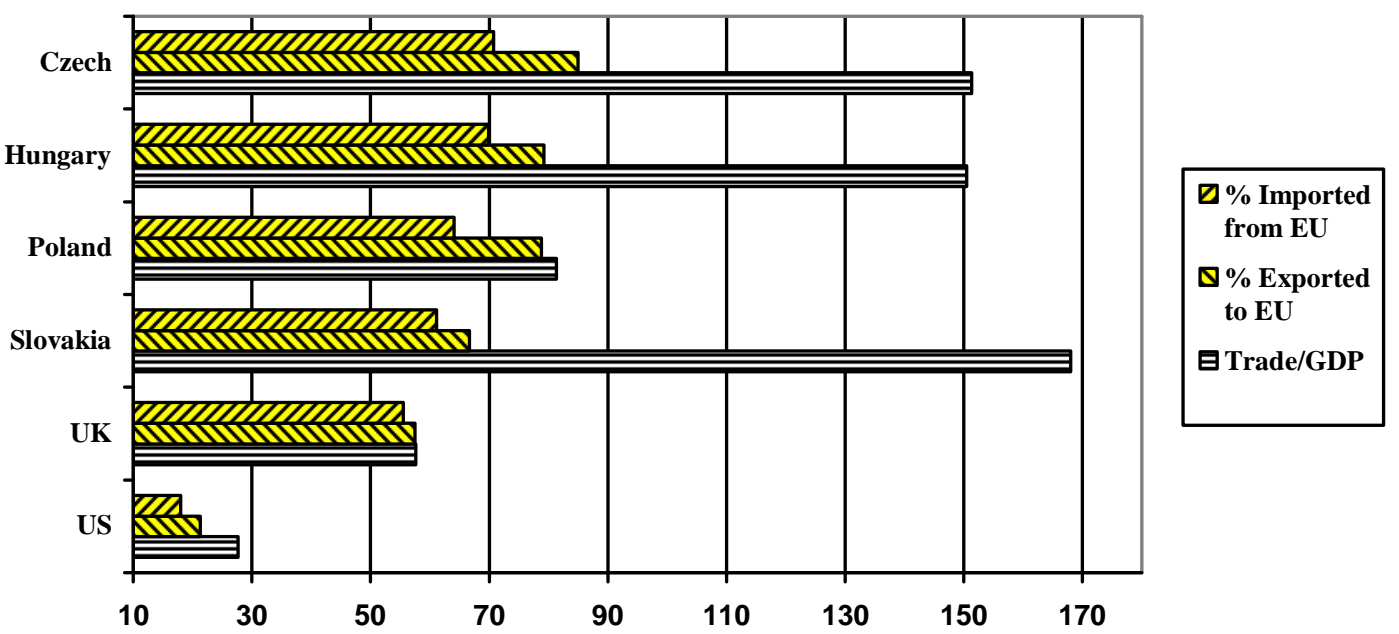

Source: WTO 
Figure 1. Trade Dependence on Europe, selected countries 


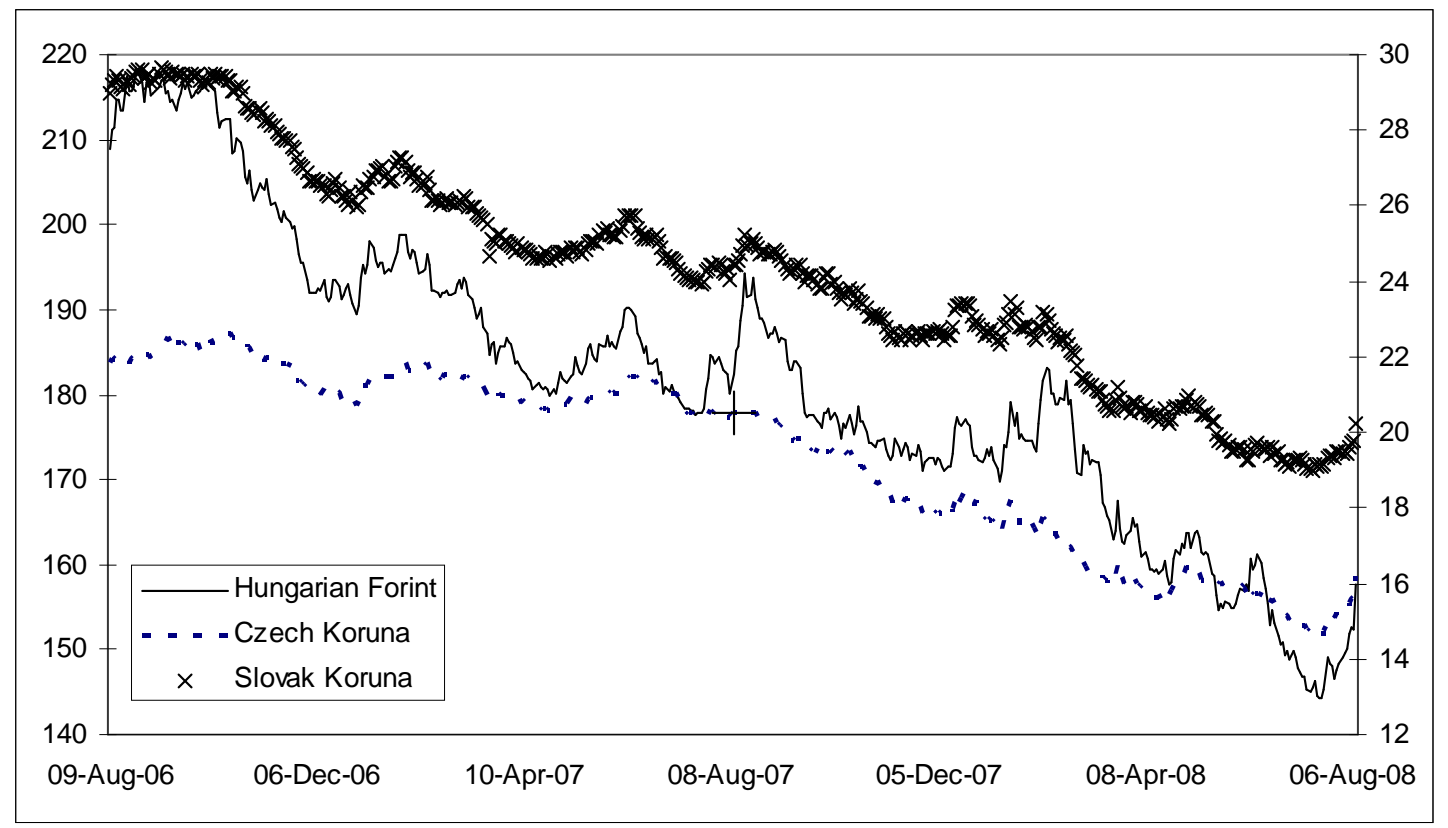

Figure 2a. The Forint, the Czech Koruna and the Slovakian Koruna against the US Dollar.

The Forint is measured on the left-hand scale 


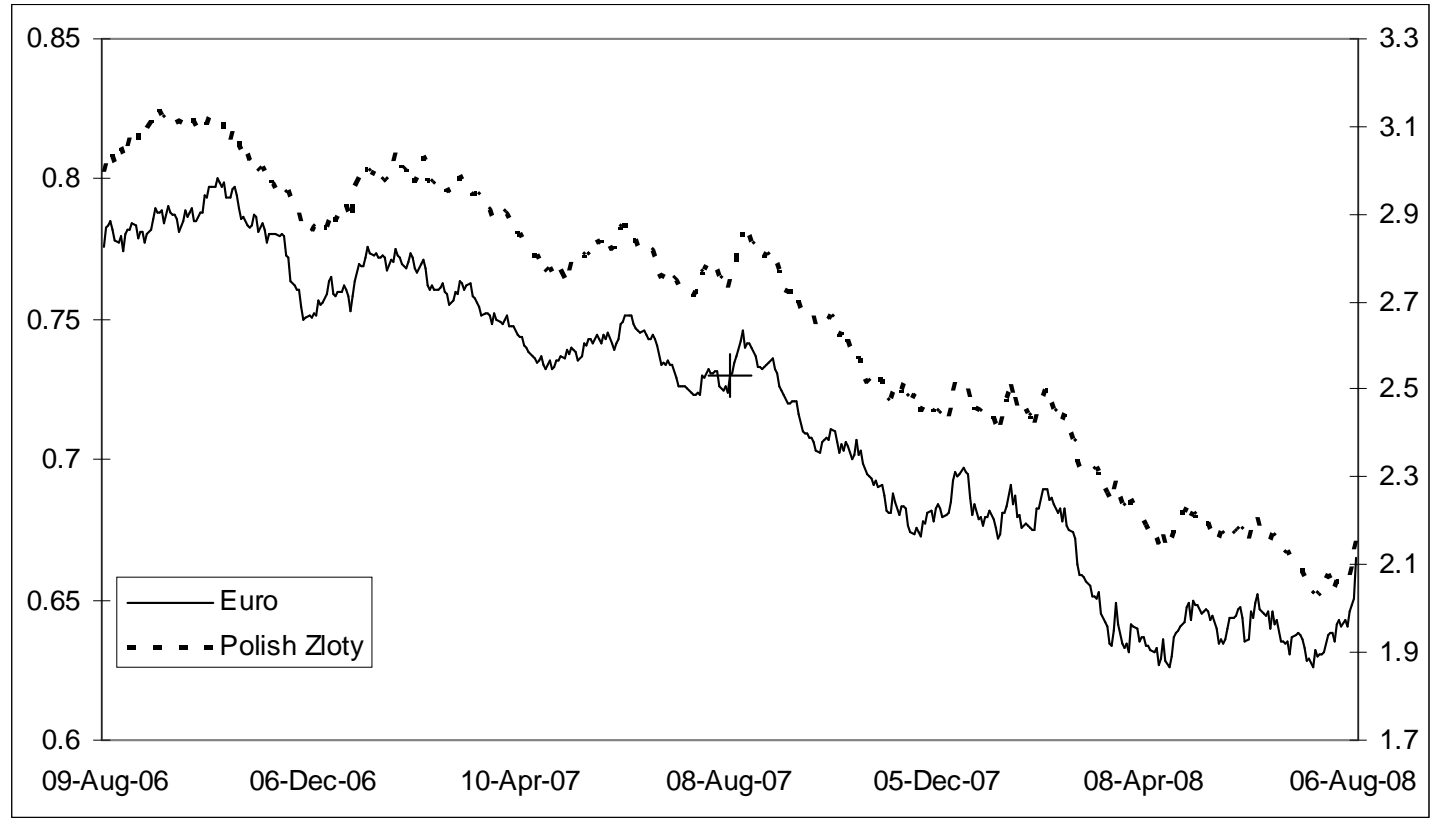

Figure 2b. The Euro and the Zloty against the US Dollar.

The Euro is measured on the left-hand scale 


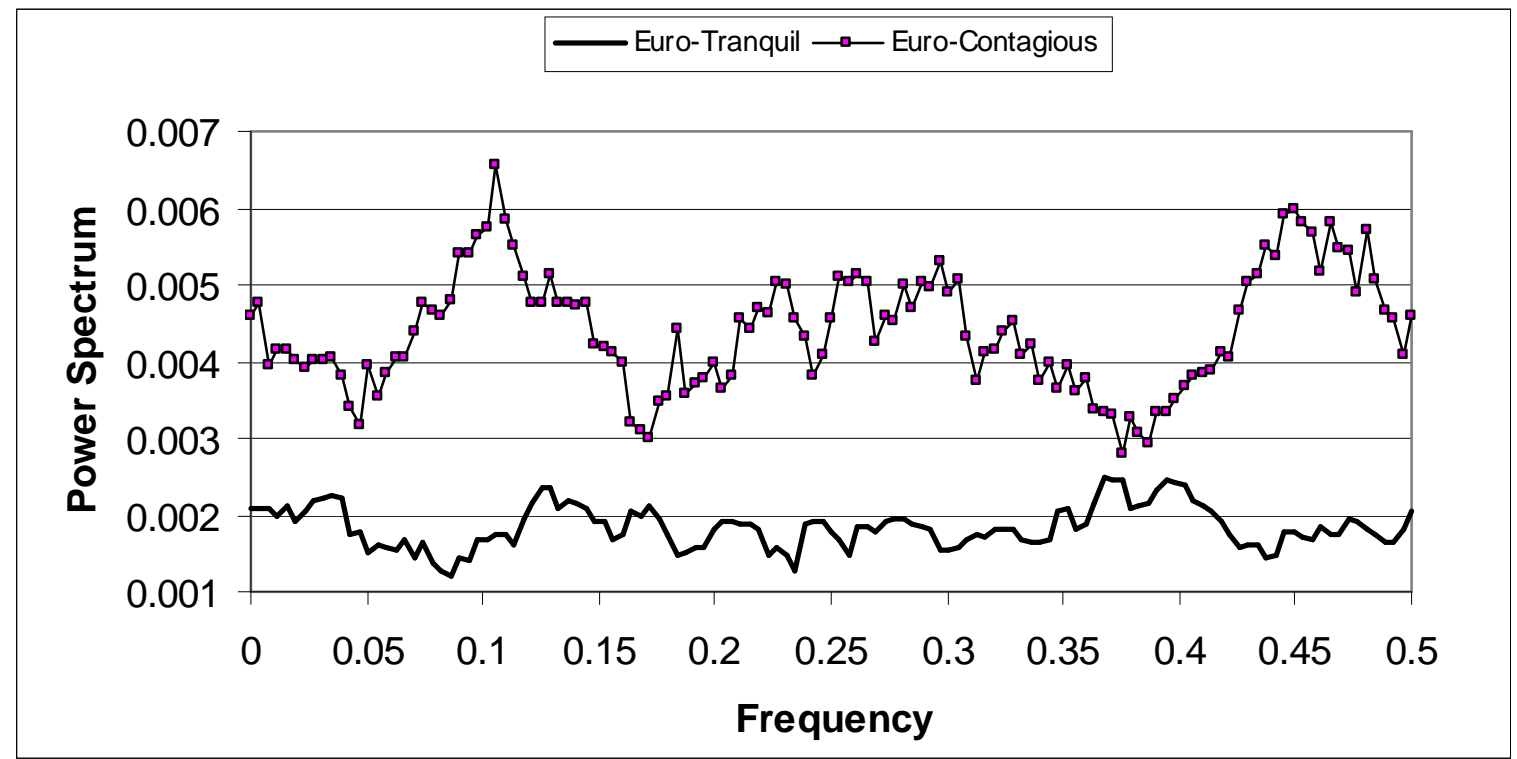

Figure 3. The Power Spectra of the Euro in Tranquil and Contagious Periods 


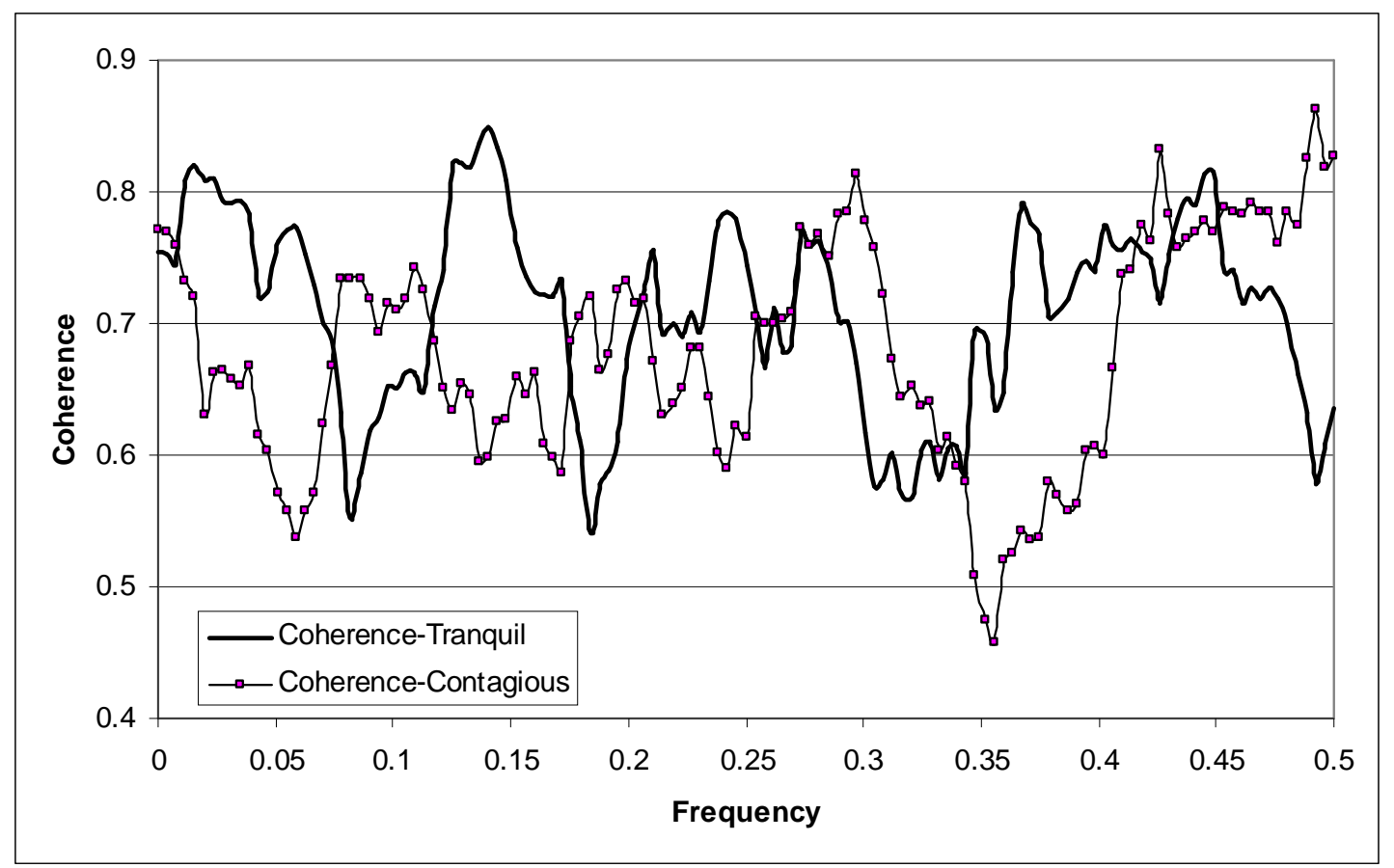

Figure 4. Coherence between the Czech Koruna and the Euro in Tranquil and Contagious Periods 


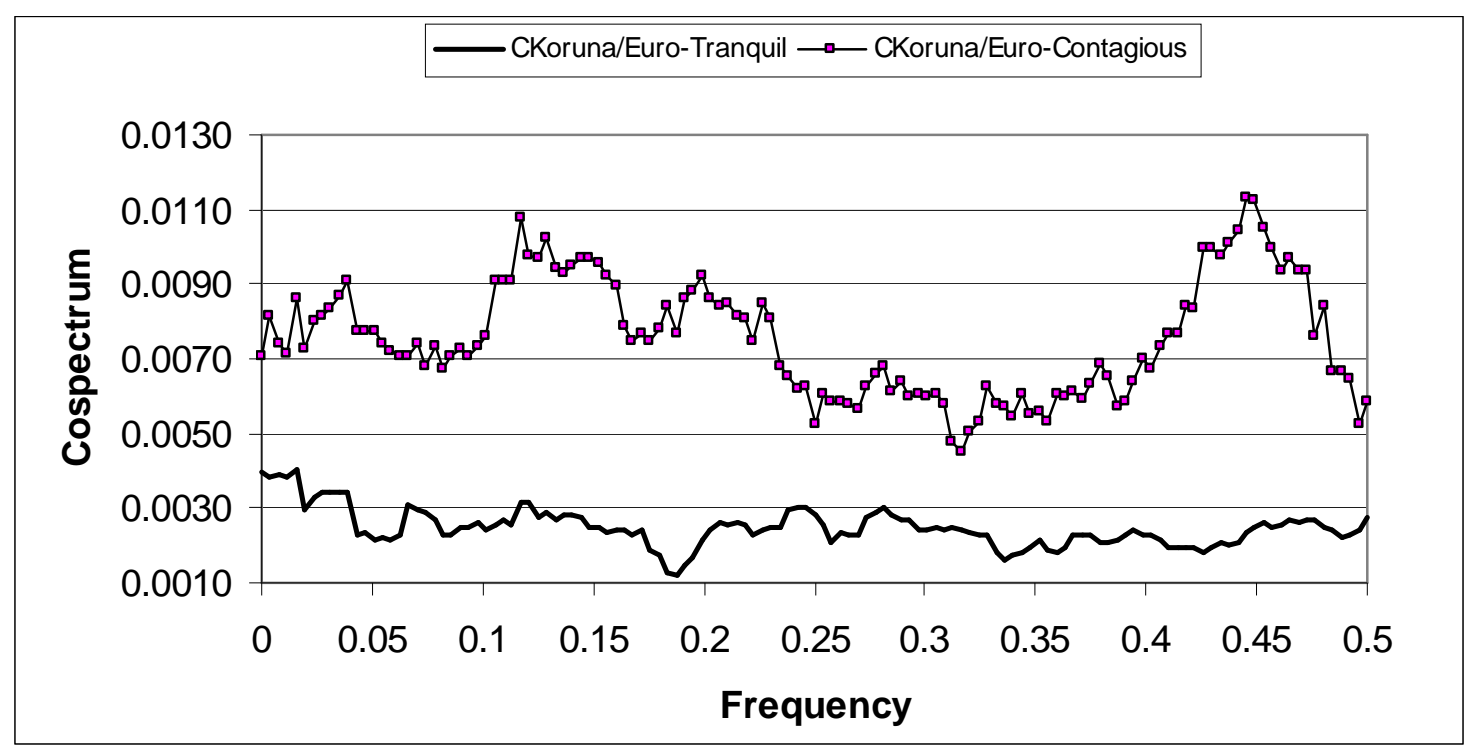

Figure 5. Cospectra between the Czech Koruna and the Euro in Tranquil and Contagious Periods 


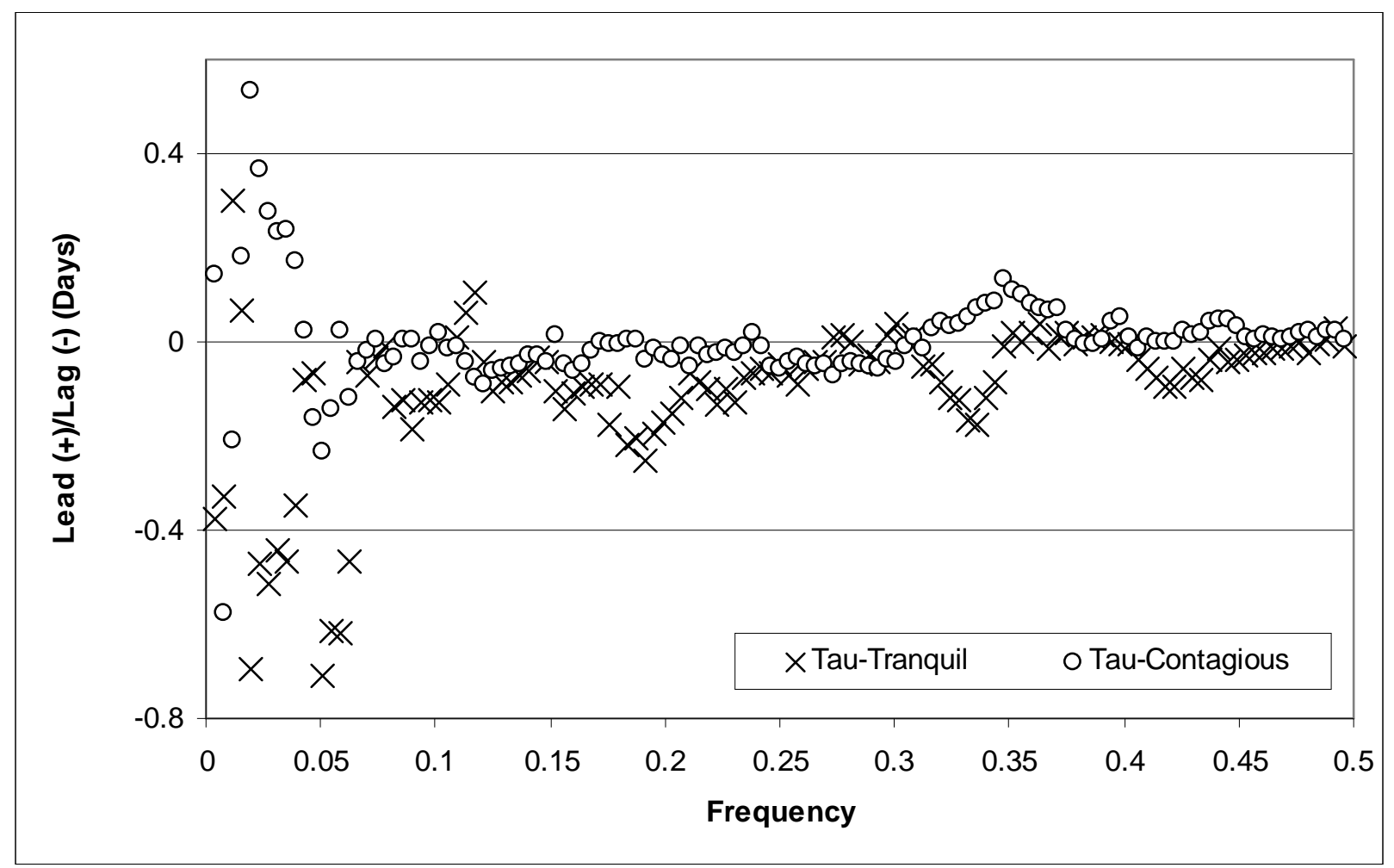

Figure 6. Tau - Euro/Zloty.

Tranquil $(x)$ and Contagious $(\circ)$ periods. If positive, the symbol indicates the Euro leads the Zloty by $\tau$ days 


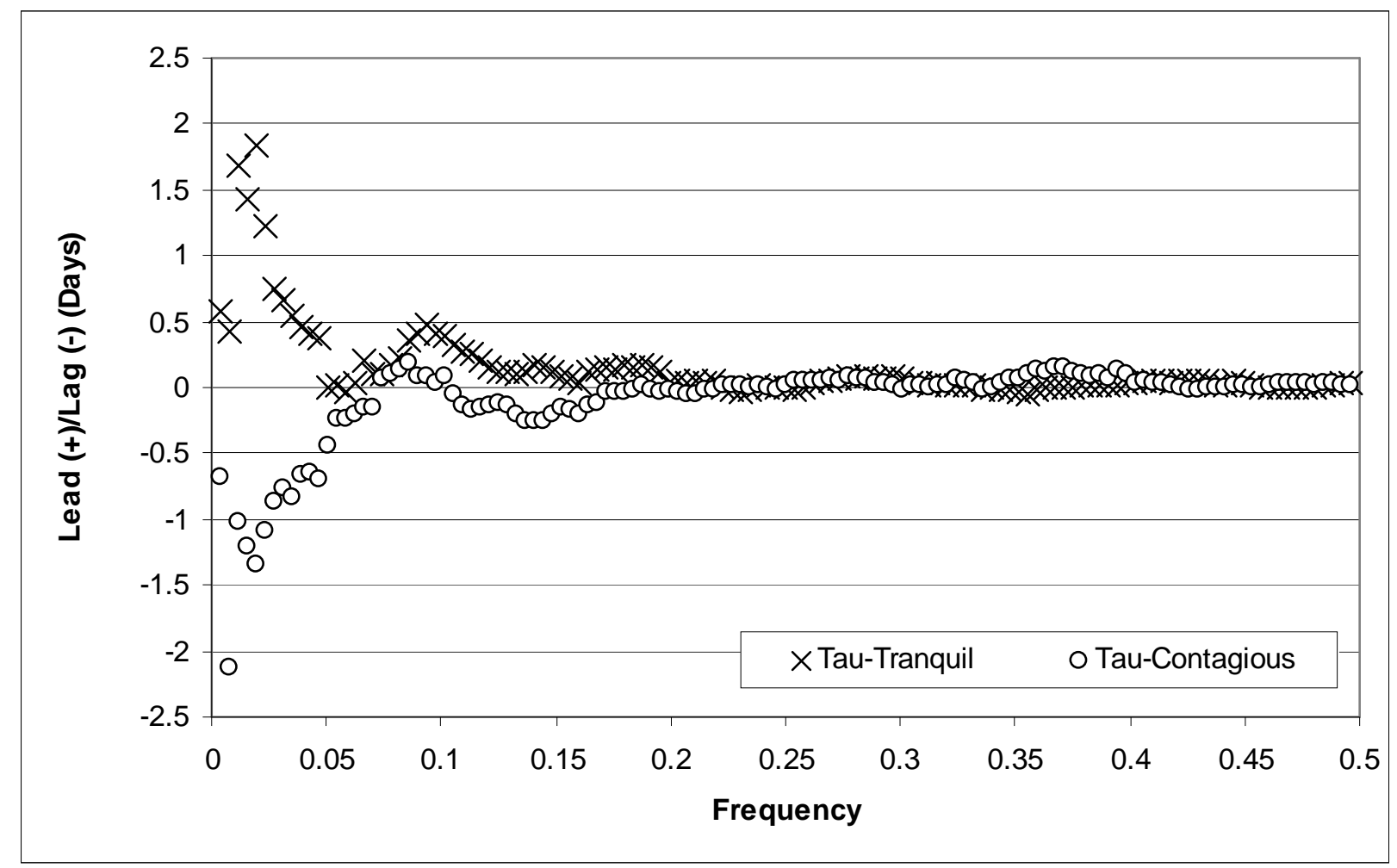

Figure 7. Tau - Euro/ Czech Koruna

Tranquil $(\times)$ and Contagious $(\circ)$ periods. If positive, the symbol indicates the Euro leads the Czech Koruna by $\tau$ days 


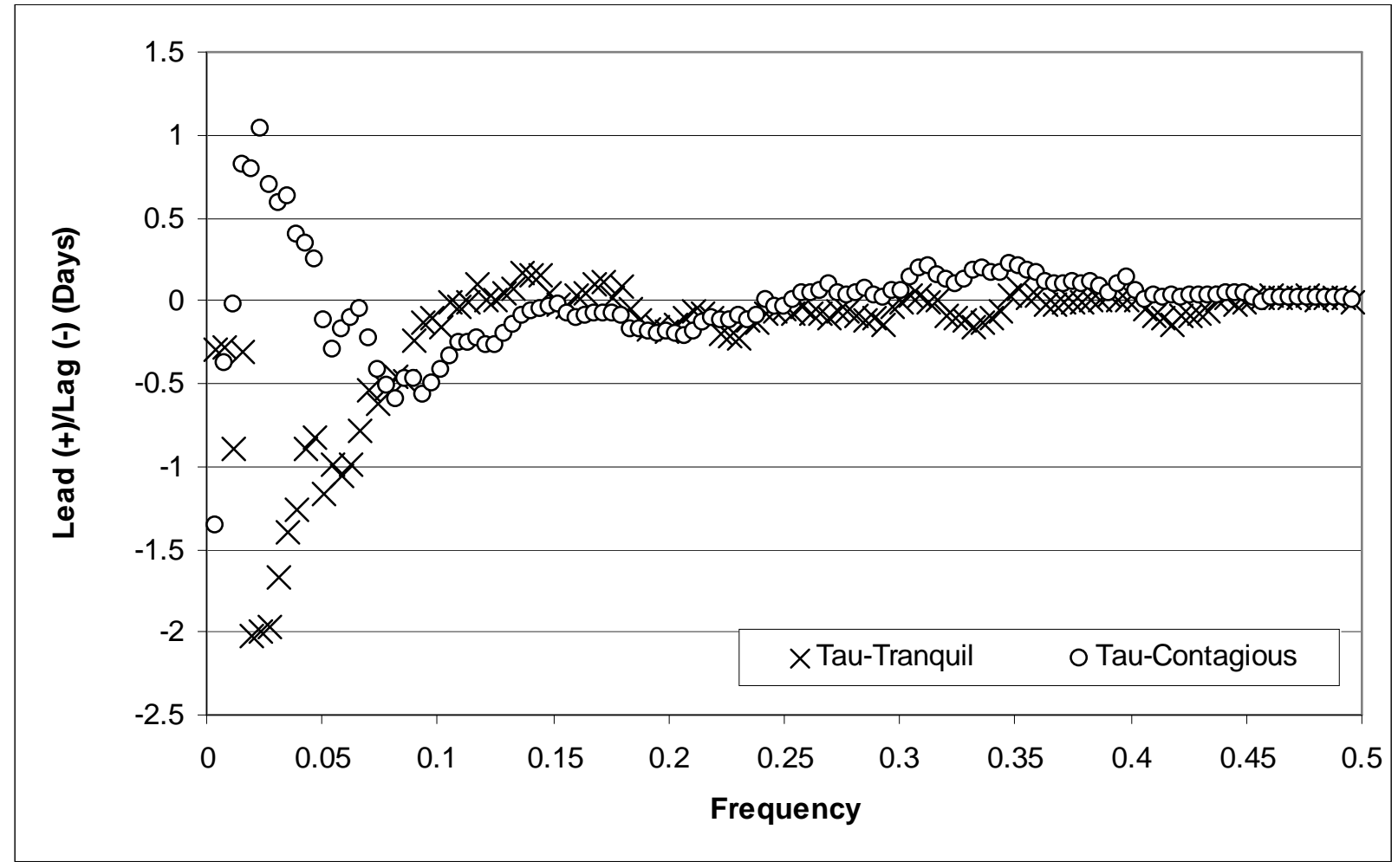

Figure 8. Tau - Euro/Forint

Tranquil $(x)$ and Contagious $(\circ)$ periods. If positive, the symbol indicates the Euro leads the Forint by $\tau$ days. 


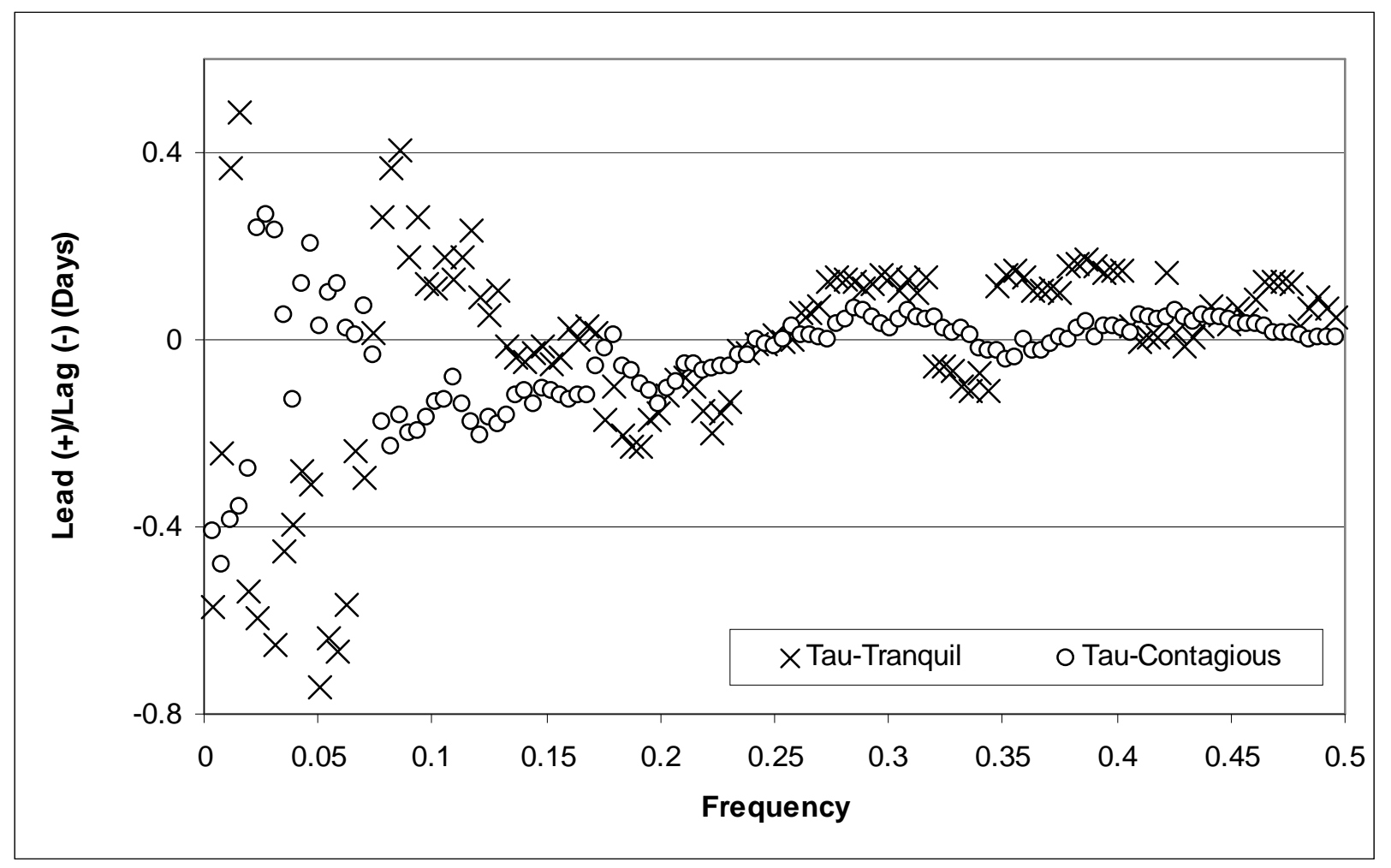

Figure 9. Tau - Euro/ Slovakian Koruna

Tranquil $(\times)$ and Contagious $(\circ)$ periods. If positive, the symbol indicates the Euro leads the Slovakian Koruna by $\tau$ days.

Table 1. Unit Root Test Results

\begin{tabular}{|c|c|c|c|c|c|}
\hline \multirow{2}{*}{ Currency } & & \multicolumn{2}{|c|}{ Tranquil period } & \multicolumn{2}{|c|}{ Contagious period } \\
\hline & & $a$ & $b$ & $a$ & $b$ \\
\hline \multirow{2}{*}{ CKoruna } & Levels & -.69058 & -1.9949 & -1.4255 & -1.7829 \\
\hline & Differenced & -15.0356 & -15.0252 & -15.6372 & -15.6769 \\
\hline \multirow{2}{*}{ Forint } & Levels & -.77303 & -2.0074 & -.62233 & -2.5720 \\
\hline & Differenced & -14.8300 & -14.7995 & -14.8811 & -14.8617 \\
\hline \multirow{2}{*}{ Zloty } & Levels & -.28052 & -2.3642 & -.76087 & -2.4315 \\
\hline & Differenced & -15.0140 & -15.0318 & -14.9967 & -14.9698 \\
\hline \multirow{2}{*}{ SKoruna } & Levels & -.57317 & -1.9792 & -.63254 & -2.6187 \\
\hline & Differenced & -15.7061 & -15.6739 & -15.4509 & -15.4199 \\
\hline \multirow{2}{*}{ Euro } & Levels & -.42713 & -2.7236 & -1.4616 & -1.7596 \\
\hline & Differenced & -16.0975 & -16.1037 & -16.4191 & -16.4391 \\
\hline \multicolumn{2}{|c|}{ Critical values } & -2.8731 & -3.4288 & -2.8731 & -3.4288 \\
\hline
\end{tabular}

$a$ intercept but not a trend $b$ an intercept and a linear trend

Lag order $p$ ( $=0$ in all cases) selected using Akaike's information criterion. 
Table 2. Descriptive Statistics of Currency Turbulence

\begin{tabular}{|c|c|c|c|c|c|}
\hline \multirow[b]{2}{*}{ Currency } & \multirow[t]{2}{*}{ Period } & \multirow{2}{*}{$\begin{array}{c}\text { Normal } \\
\text { Test } \\
p \text {-value }\end{array}$} & \multirow[t]{2}{*}{$\begin{array}{c}\text { Std. } \\
\text { Deviation }\end{array}$} & \multicolumn{2}{|c|}{$\begin{array}{c}\text { Homogeneous } \\
\text { Variance }\end{array}$} \\
\hline & & & & $F$ & $p$-value \\
\hline CKoruna & Tranquil & .748 & .0040843 & 49.759 & .000 \\
\hline \multirow{2}{*}{ Forint } & Tranquil & .506 & .0059034 & \multirow{2}{*}{19.677} & \multirow{2}{*}{.000} \\
\hline & Contagious & .642 & .0085193 & & \\
\hline Zloty & Tranquil & .388 & .0047997 & 23.023 & .000 \\
\hline \multirow{2}{*}{ SKoruna } & Tranquil & .558 & .0052927 & \multirow{2}{*}{18.745} & \multirow{2}{*}{.000} \\
\hline & Contagious & .480 & .0069142 & & \\
\hline \multirow{2}{*}{ Euro } & Tranquil & .412 & .0035292 & \multirow[t]{2}{*}{31.588} & \multirow{2}{*}{.000} \\
\hline & Contagious & .310 & .0056126 & & \\
\hline
\end{tabular}


Table 3. Correlation Coefficients

\begin{tabular}{|l|l|l|l|l|l|l|l|l|l|}
\hline $\begin{array}{l}\text { Currency } \\
\text { Pairing }\end{array}$ & $\begin{array}{l}\text { Corr } \\
-\mathrm{a}\end{array}$ & $\begin{array}{l}\text { Corr } \\
-\mathrm{b}\end{array}$ & $\begin{array}{l}\text { Un } p \text { - } \\
\text { value }\end{array}$ & $\begin{array}{l}\text { FR } \\
p- \\
\text { value }\end{array}$ & $\begin{array}{l}\text { Currency } \\
\text { Pairing }\end{array}$ & $\begin{array}{l}\text { Corr } \\
-\mathrm{a}\end{array}$ & $\begin{array}{l}\text { Corr } \\
-\mathrm{b}\end{array}$ & $\begin{array}{l}\text { Un } p \text { - } \\
\text { value }\end{array}$ & $\begin{array}{l}\text { FR } p \text { - } \\
\text { value }\end{array}$ \\
\hline Euro/CKoruna & $0.830 \downarrow$ & 0.838 & 0.772 & 0.119 & CKoruna/Zloty & $0.824 \uparrow$ & 0.719 & $\mathbf{0 . 0 0 3}$ & 0.951 \\
\hline Euro/Forint & $0.767 \uparrow$ & 0.626 & $\mathbf{0 . 0 0 2}$ & 0.508 & CKoruna/SKoruna & $0.797 \uparrow$ & 0.579 & $\mathbf{0 . 0 0 2}$ & 0.846 \\
\hline Euro/SKoruna & $0.886 \uparrow$ & 0.675 & $\mathbf{0 . 0 0 0}$ & $\mathbf{0 . 0 2 0}$ & SKoruna/Forint & $0.778 \uparrow$ & 0.708 & 0.078 & 0.978 \\
\hline Euro/Zloty & $0.874 \uparrow$ & 0.738 & $\mathbf{0 . 0 0 0}$ & 0.185 & Zloty/Forint & $0.840 \uparrow$ & 0.815 & 0.375 & 0.973 \\
\hline CKoruna/Forint & $0.683 \uparrow$ & 0.583 & 0.059 & 0.856 & Zloty/SKoruna & $0.855 \uparrow$ & 0.739 & $\mathbf{0 . 0 0 0}$ & 0.164 \\
\hline
\end{tabular}

a: Contagious period b: Tranquil period

Un: significance level using Unadjusted coefficients; FR: Forbes-Rigobon

$p$ - values in bold are significant at the $5 \%$ level 
Table 4. Coherence Values - Descriptive Statistics and Tests

\begin{tabular}{|c|c|c|c|c|c|c|c|c|}
\hline & Mean & $\begin{array}{c}\text { Std. } \\
\text { Deviation }\end{array}$ & Median & Max & Normality & $\begin{array}{c}\text { Skew } \\
\mathrm{se}=.213\end{array}$ & Wilcoxon & Sign \\
\hline CKoruna/Forint-a & $0.45 \uparrow$ & 0.13 & 0.46 & 0.71 & .420 & -.041 & \multirow{2}{*}{.000} & \multirow{2}{*}{.000} \\
\hline CKoruna/Forint-b & 0.36 & 0.12 & 0.35 & 0.59 & .713 & -.002 & & \\
\hline CKoruna/SKoruna-a & $0.67 \uparrow$ & 0.10 & 0.63 & 0.88 & .817 & -.262 & \multirow{2}{*}{.000} & \multirow{2}{*}{.000} \\
\hline CKoruna/SKoruna-b & 0.48 & 0.18 & 0.49 & 0.80 & .533 & .036 & & \\
\hline CKoruna/Zloty-a & $0.66 \uparrow$ & 0.10 & 0.68 & 0.84 & .064 & -.728 & \multirow{2}{*}{.000} & \multirow{2}{*}{.000} \\
\hline CKoruna/Zloty-b & 0.52 & 0.11 & 0.50 & 0.69 & .052 & -.240 & & \\
\hline Euro/CKoruna-a & $0.68 \downarrow$ & 0.09 & 0.68 & 0.86 & .330 & -.220 & \multirow{2}{*}{.008} & \multirow{2}{*}{.218} \\
\hline Euro/CKoruna-b & 0.71 & 0.07 & 0.72 & 0.85 & .426 & -.394 & & \\
\hline Euro/Forint-a & $0.58 \uparrow$ & 0.11 & 0.60 & 0.77 & .378 & -.733 & \multirow{2}{*}{.000} & \multirow{2}{*}{.000} \\
\hline Euro/Forint-b & 0.41 & 0.12 & 0.42 & 0.66 & .081 & -.329 & & \\
\hline Euro/SKoruna-a & $0.78 \uparrow$ & 0.05 & 0.79 & 0.90 & .092 & -.043 & \multirow{2}{*}{.000} & \multirow{2}{*}{.000} \\
\hline Euro/SKoruna-b & 0.48 & 0.17 & 0.52 & 0.80 & .150 & -.349 & & \\
\hline Euro/Zloty-a & $0.75 \uparrow$ & 0.07 & 0.76 & 0.87 & .571 & -.416 & \multirow{2}{*}{.000} & \multirow{2}{*}{.000} \\
\hline Euro/Zloty-b & 0.55 & 0.13 & 0.55 & 0.82 & .208 & -.419 & & \\
\hline SKoruna/Forint-a & $0.60 \uparrow$ & 0.08 & 0.60 & 0.77 & .212 & -.213 & \multirow{2}{*}{.000} & \multirow{2}{*}{.000} \\
\hline SKoruna/Forint-b & 0.52 & 0.15 & 0.53 & 0.88 & .277 & .080 & & \\
\hline Zloty/Forint-a & $0.69 \uparrow$ & 0.08 & 0.70 & 0.82 & .624 & -.643 & \multirow{2}{*}{.041} & \multirow{2}{*}{.218} \\
\hline Zloty/Forint-b & 0.67 & 0.06 & 0.68 & 0.82 & .291 & -.250 & & \\
\hline Zloty/SKoruna-a & $0.73 \uparrow$ & 0.07 & 0.72 & 0.88 & .863 & .302 & \multirow{2}{*}{.000} & \multirow{2}{*}{.000} \\
\hline Zloty/SKoruna-b & 0.57 & 0.14 & 0.55 & 0.85 & .705 & .046 & & \\
\hline
\end{tabular}

$\mathrm{a}$ : Contagious period b: Tranquil period 
Table 5. Orlov's Measures of Non-linear Change in the Cospectrum

\begin{tabular}{|c|c|c|c|c|c|c|c|c|c|}
\hline \multirow{2}{*}{$\begin{array}{l}\text { Currency } \\
\text { pair }\end{array}$} & \multicolumn{2}{|c|}{$f>0.4$} & \multicolumn{2}{|c|}{$f>0.45$} & \multirow{2}{*}{$\begin{array}{l}\text { Currency } \\
\text { pair }\end{array}$} & \multicolumn{2}{|c|}{$f>0.4$} & \multicolumn{2}{|c|}{$f>0.45$} \\
\hline & $\begin{array}{l}\% \\
\text { hange }\end{array}$ & $\begin{array}{l}\text { Ratio of } \\
\text { change }\end{array}$ & $\begin{array}{c}\% \\
\text { change }\end{array}$ & $\begin{array}{c}\% \\
\text { change }\end{array}$ & & $\begin{array}{c}\% \\
\text { change }\end{array}$ & $\begin{array}{l}\text { Ratio of } \\
\text { change }\end{array}$ & $\begin{array}{c}\% \\
\text { change }\end{array}$ & $\begin{array}{l}\text { Ratio of } \\
\text { change }\end{array}$ \\
\hline Iro/SKoru & 281.3 & 1.5 & 346.0 & 1.7 & CKoruna/Zloty & 265.9 & 1.3 & 250.6 & 1.3 \\
\hline Furo/71oty & 1.8 & 1.2 & 240.1 & 1.3 & $\mathrm{CK}$ & 363.7 & 1.8 & 394.6 & 1.9 \\
\hline $\mathrm{ro} / \mathrm{l}$ & 5.6 & 1 & 193 & 1.1 & Zlot & 151.1 & 1.2 & 4 & 1.2 \\
\hline $\mathrm{ro} / \mathrm{C}$ & 24.5 & 1.2 & 229.7 & 1.2 & Forin & 121.7 & 1.3 & 107.1 & 1.2 \\
\hline na/Forint & 48.8 & 1.3 & 237.8 & 1.2 & 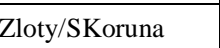 & 191.7 & 1.4 & 210.8 & 1.5 \\
\hline
\end{tabular}

